\title{
The Tissue-Resident Marker CD103 on Peripheral Blood T Cells Predicts Responses to Anti-PD-1 Therapy in Gastric Cancer
}

Yohei Nose

Osaka University

Takuro Saito ( $\nabla$ tsaito@gesurg.med.osaka-u.ac.jp )

Osaka University

Kei Yamamoto

Osaka University

Kotaro Yamashita

Osaka University

Koji Tanaka

Osaka University

Kazuyoshi Yamamoto

Osaka University

Tomoki Makino

Osaka University

Tsuyoshi Takahashi

Osaka University

Atsunari Kawashima

Osaka University

Miya Haruna

Osaka University

Michinari Hirata

Osaka University

Azumi Ueyama

Osaka University

Kota Iwahori

Osaka University

Yukinori Kurokawa

Osaka University

Hidetoshi Eguchi

Osaka University

Yuichiro Doki 
Osaka University

\section{Hisashi Wada}

Osaka University

\section{Research Article}

Keywords: CD103, Clinical response, Gastric cancer, Nivolumab, Predictive biomarker

Posted Date: March 7th, 2022

DOI: https://doi.org/10.21203/rs.3.rs-1415877/v1

License: (c) (1) This work is licensed under a Creative Commons Attribution 4.0 International License. Read Full License 


\section{Abstract \\ Background}

Immune checkpoint inhibitors (ICls) have revolutionized cancer treatment. Since clinical benefits are limited to a subset of patients, we aimed to identify peripheral blood biomarkers that predict the efficacy of the anti-programmed cell death protein 1 (PD-1) antibody (nivolumab) in patients with gastric cancer.

\section{Methods}

We collected peripheral blood samples from gastric cancer patients $(n=29)$ before and after treatment with nivolumab and investigated the relationship between the frequency of the surface or intracellular markers among nivolumab-binding $\mathrm{PD}-\mathrm{1}^{+} \mathrm{CD} 8^{+} \mathrm{T}$ cells and treatment responses using multicolor flow cytometry. The tumors, lymph nodes, and peripheral blood of gastric cancer patients who underwent gastrectomy following nivolumab treatment were collected, and nivolumab-binding PD- $1^{+} \mathrm{CD} 8^{+} \mathrm{T}$ cells in these tissue samples were characterized.

\section{Results}

Patients with a high frequency of $\mathrm{CD} 103$ among PD $-1^{+} \mathrm{CD} 8^{+} \mathrm{T}$ cells in peripheral blood 2 weeks after the start of treatment had significantly better progression-free survival than the low group $(P=0.032)$. This $\mathrm{CD} 103^{+} \mathrm{PD}-1^{+} \mathrm{CD} 8^{+} \mathrm{T}$ cell population mainly consisted of central memory $\mathrm{T}$ cells, showing the high expression of Ki-67 and few cytotoxic granules. Whereas, effector memory T cells were more frequently observed among CD103 ${ }^{+} \mathrm{PD}-1^{+} \mathrm{CD} 8^{+} \mathrm{T}$ cells in tumors, which implied a change in the differentiated status of central memory $T$ cells in lymph nodes and peripheral blood to effector memory $T$ cells in tumors during the treatment with ICls.

\section{Conclusions}

A high frequency of $\mathrm{CD} 103$ among PD $-1^{+} \mathrm{CD} 8^{+} \mathrm{T}$ cells 2 weeks after nivolumab treatment in patients with advanced gastric cancer may be a useful biomarker for predicting the efficacy of anti-PD-1 therapy.

\section{Introduction}

Antibodies that block the programmed cell death protein 1 (PD-1) pathway have demonstrated potent anti-tumor activity in cancer patients and are now an approved treatment for several cancers (1). Although a significant number of patients benefit from immune checkpoint inhibitors (ICls), clinical efficacy is limited to a subset of patients. Therefore, extensive efforts have been made to identify biomarkers that predict responses to this therapy (2). As predictive markers in the tumor 
microenvironment, the tumor expression of programmed death ligand 1 (PD-L1), the intensity of intratumoral $\mathrm{CD}^{+} \mathrm{T}$ cell infiltration, and the tumor mutational burden have been proposed as biomarkers for responses to ICls (2). Tumor PD-L1 expression is now used as the indication for anti-PD-1 therapy for patients with non-small cell lung cancer because of its proven relationship with clinical responses to this treatment $(3,4)$. However, tumor PD-L1 expression was not identified as a predictor of the therapeutic effects of anti-PD-1 therapy in the ATTRACTION-2 trial, which assessed the clinical efficacy of anti-PD-1 therapy for gastric cancer, and there is currently no clinically available biomarker that predicts the therapeutic efficacy of ICls for gastric cancer (5).

Since there are limitations to the use of tumor factors in terms of frequent sample availability, particularly for visceral tumors, more easily applicable markers need to be considered for routine clinical use. Peripheral blood samples are more easily available than tumor samples and offer information on dynamic changes serially before and after treatment. Therefore, an analysis of blood may provide valuable insights into dynamic changes in T cell responses during treatment with ICls (6-8).

The mechanisms underlying the efficacy of anti-PD-1 therapy, namely, what cells function for anti-tumor immunity and when are these cells attracted to the tumor microenvironment during treatment with ICls, have not yet been elucidated. Since the anti-PD-1 antibody binds to PD-1-expressing cells, it appears to be important to focus on the characteristics of anti-PD- 1 antibody-binding T cells, which may play a major role in responses to ICls (9). Since anti-PD-1 antibody-binding T cells have been detected more than 20 weeks after the last infusion of anti-PD-1 therapy, changes in this cell population may be examined over time after the initiation of treatment with ICls (10).

Therefore, we herein aimed to identify peripheral blood biomarkers that predict the efficacy of anti-PD-1 therapy (nivolumab) and characterize cell populations by analyzing nivolumab-binding $T$ cells in patients with advanced gastric cancer.

\section{Materials And Methods}

\section{Study design and patients}

The present study was conducted to identify peripheral blood biomarkers that predict the efficacy of nivolumab using analyses of peripheral blood lymphocytes serially before and after nivolumab therapy in patients with gastric cancer. We enrolled twenty-nine consecutive patients with recurrent or metastatic gastric cancer who were refractory to standard therapy and were treated with nivolumab between April 2017 and March 2019 at Osaka University Hospital. These patients received 3 mg/kg nivolumab every 2 weeks in 6-week cycles (Fig. 1a). Treatment was continued until disease progression, death, unacceptable toxic effects, or a patient's request to discontinue. All patients provided written informed consent before tissue sampling according to the guidelines of the Declaration of Helsinki. The present study was approved by the Institutional Ethics Committee of Osaka University Hospital (Osaka, Japan) (approval number; \#13266). 


\section{Evaluation}

A physical examination and laboratory tests were performed every 2 weeks, and tumor responses were assessed by computed tomography (CT) every 6 weeks. The best overall response (BOR) was assessed according to the Response Evaluation Criteria in Solid Tumors, version 1.1 (RECIST v1.1) based on the results of $C T$ examinations using the following categories: complete response (CR), partial response (PR), stable disease (SD), progressive disease (PD), and not evaluable (NE). Progression-free survival (PFS) was defined as the time from the start of nivolumab to either disease progression or death from any cause. Overall survival (OS) was defined as the time from the start of nivolumab to death from any cause.

\section{Peripheral blood and tissue samples}

Peripheral blood samples were collected before treatment and 2 and 6 weeks after the initiation of nivolumab. Peripheral blood mononuclear cells (PBMCs) were isolated from blood samples and stored in the $\mathrm{N}_{2}$ bank. Tumor and lymph node samples in addition to blood samples were collected from two patients who had undergone surgical resection of the stomach after treatment with nivolumab. To collect tissue-infiltrating lymphocytes, fresh tumor and lymph node tissues were minced and treated with gentleMACS Dissociator (Miltenyi Biotec, Bergisch Gladbach, Germany) as previously described (8). Extracted lymphocytes were stored in the $\mathrm{N}_{2}$ bank and analyzed with a LSR Fortessa cytometer (BD Biosciences, San Jose, USA) after thawing and washing.

\section{Antibody and multicolor flow cytometry}

The fluorescence-labeled antibodies used in the present study were as follows: anti-CD3 (clone UCHT1; BioLegend, San Diego, CA), CD4 (clone OKT4; BioLegend), CD8 (clone RPA-T8; BioLegend), CD27 (clone L128; BD Biosciences), CD45RA (clone HI100; BioLegend), ICOS (clone ISA-3; eBioscience), PD-1 (clone EH12.1; BD Biosciences), CD103 (clone Ber-ACT8; BioLegend), T cell immunoglobulin mucin domain 3 (Tim-3, clone F38-2E2; BioLegend), TNFa (clone Mab11; Invitrogen), IL-2 (clone MQ1-17H12; eBioscience), IFN-y (clone 4S.B3; BioLegend), Granzyme B (clone GB12; Invitrogen), Perforin (clone B-D48; BioLegend), Ki-67 (clone Ki-67; BioLegend), and the anti-human IgG4 antibody, biotin (clone HP6025; Invitrogen) followed by secondary staining with streptavidin. Dead cells were identified using the LIVE/DEAD Fixable Red Dead Cell Stain Kit (Invitrogen). Corresponding isotype control antibodies were purchased from the same manufacturer. To detect PD-1 ${ }^{+} \mathrm{T}$ cells after the nivolumab treatment, the antibody was substituted by the anti-IgG4 antibody because PD-1 molecules were completely and stably covered by nivolumab (human IgG4). We confirmed that the detection rate of the anti-IgG4 antibody against PD- $1^{+} \mathrm{CD} 8^{+} \mathrm{T}$ cells treated with nivolumab in vitro was similar to that of the anti-PD-1 antibody against untreated PD- $1^{+} \mathrm{CD} 8^{+}$ T cells (Supplementary Fig. 1a).

In the flow cytometric analysis, thawed cells were incubated with antibodies at $4^{\circ} \mathrm{C}$ for 30 minutes after washing. Washed cells were analyzed with a LSR Fortessa cytometer (BD Biosciences) and the data 
obtained were analyzed using BD FACS Diva software. Regarding intracellular staining, thawed cells were stained with antibodies to surface antigens and a fixable viability dye (eBioscience) at $4^{\circ} \mathrm{C}$ for 30 minutes. After being incubated, cells were washed, fixed, and permeabilized with fix/perm solution (BD Biosciences) at $4^{\circ} \mathrm{C}$ for 15 minutes. Cells were then stained with antibodies for intracellular molecules at $4^{\circ} \mathrm{C}$ for 30 minutes.

\section{Assessment of cytokine production}

Cytokine production was assessed in a sample 2 weeks after the initiation of nivolumab from one patient. PBMCs were separated into nivolumab-binding PD-1 ${ }^{+}$cells and PD-1 ${ }^{-}$cells with a cell sorter (MACSQuant ${ }^{\circledR}$ Analyzer; Miltenyi Biotec, Bergisch Gladbach, Germany) and separated cells were then stimulated with $50 \mathrm{ng} / \mathrm{ml}$ PMA (Sigma-Aldrich, Saint Louis, MO), $1 \mu \mathrm{g} / \mathrm{ml}$ ionomycin (Sigma-Aldrich), and Golgi Plug reagent (BD Biosciences) at $37^{\circ} \mathrm{C}$ for 5 hours. Harvested cells were washed and used for intracellular staining. $f$

\section{Statistical analysis}

Differences between the two groups in each experiment were analyzed using the Student's $t$-test or MannWhitney U test, where appropriate. Categorical variables and continuous variables were compared as indicated in the figure captions. All FCS files were uploaded and evaluated using Cytobank software, a web-based platform for storing, exploring, and sharing cytometry data [http://www.cytobank.org]. To assess whether biomarkers had an independent significant effect on survival, we performed univariate and multivariate Cox regression analyses with adjustments for age, sex, previous gastrectomy, blood test results before the nivolumab treatment, and the ratio of the frequency of each surface or intracellular marker among PD $-1^{+} \mathrm{CD} 8^{+} \mathrm{T}$ cells in peripheral blood 2 weeks after the start of the nivolumab treatment to that before treatment. Survival curves were calculated using the Kaplan-Meier method and differences were assessed using the Log-rank test. The high and low groups were divided by the median values of each factor. A value of $P<0.05$ was considered to be significant. All statistical analyses were performed using JMP Pro 14 Discovery ${ }^{\text {TM }}$ (SAS Institute Inc., Cary, NC).

\section{Results}

\section{Patient characteristics}

Patient characteristics at baseline are summarized in Table 1. Eighteen out of 29 patients $(62.1 \%)$ had recurrence after gastrectomy. All patients received two or more lines of previous systemic chemotherapy before the nivolumab treatment and had no previous treatment with other ICls.

\section{Clinical responses}

The median duration of the nivolumab treatment was 1.9 months (range; 0.4 - 43.9 months). Median PFS and OS were 1.8 months (range; 0.4 - 45.5 months) and 6.7 months (range; 0.7 - 45.5 months), 
respectively. BOR was PR in 3 patients (10.3\%), SD in 2 (6.9\%), PD in 21 (72.4\%), and NE in 3 (10.3\%) (Table 2). All three cases of NE were clinically diagnosed as PD. Patients were classified into the responder group of $\mathrm{CR}, \mathrm{PR}$, and $\mathrm{SD}$ and the non-responder group of $\mathrm{PD}$ and $\mathrm{NE}$ for further analyses.

\section{The expression frequency of each marker among PD- $1^{+} \mathrm{CD} 8^{+} \mathrm{T}$ cells in peripheral blood after the nivolumab treatment}

Peripheral blood samples were collected from 29 patients before treatment, 25 patients after 2 weeks of treatment, and 19 patients after 6 weeks of treatment. PD- $1^{+} T$ cells before and after the nivolumab treatment were detected with the anti-PD-1 antibody and anti-IgG4 antibody, respectively (Supplementary Fig. 1b). We initially evaluated the expression frequency of the surface or intracellular markers among $\mathrm{PD}-1^{+} \mathrm{CD} 8^{+} \mathrm{T}$ cells or PD- $1^{-} \mathrm{CD} 8^{+} \mathrm{T}$ cells in peripheral blood before and after the nivolumab treatment, including activation marker CD103, naive marker CD45RA, immune checkpoint molecules Tim-3, ICOS and CD27, and proliferative marker Ki-67 (Fig. 1b, Supplementary Fig. 1C, 2). The frequency of each marker, except for CD45RA, was higher among PD- $1^{+} \mathrm{CD} 8^{+} \mathrm{T}$ cells than among PD- ${ }^{-} \mathrm{CD} 8^{+} \mathrm{T}$ cells at all time points. Furthermore, the frequencies of CD103, Tim-3, ICOS, and Ki-67 among PD- $1^{+} \mathrm{CD} 8^{+} \mathrm{T}$ cells rapidly increased after the start of the nivolumab treatment and were sustained for 6 weeks (Fig. 1b, Supplementary Fig. 1c). On the other hand, changes in the frequency of each marker among PD- $1^{-} \mathrm{CD} 8^{+} \mathrm{T}$ cells were smaller than those observed among PD $-1^{+} \mathrm{CD} 8^{+} \mathrm{T}$ cells. Since a larger change was observed in the frequency of each marker, particularly among PD $-1^{+} \mathrm{CD} 8^{+} \mathrm{T}$ cells, the ratio of the frequency of each marker among PD- $1^{+} \mathrm{CD} 8^{+} \mathrm{T}$ cells 2 or 6 weeks after the start of the nivolumab treatment to that before treatment (\% of each marker $2 \mathrm{w}$ or $6 \mathrm{w} / \mathrm{pre}$ ) was compared between the responder and non-responder groups (Fig. 2a, 2b). The ratio of the frequency of $\mathrm{CD} 103$ among PD $-1^{+} \mathrm{CD} 8^{+} \mathrm{T}$ cells in peripheral blood 2 weeks after the start of the nivolumab treatment to that before treatment was significantly higher in the responder group than in the non-responder group $(P=0.038)$. No significant differences were observed in the ratio of the frequencies of other markers among PD- $1^{+} \mathrm{CD} 8^{+} \mathrm{T}$ cells in peripheral blood 2 or 6 weeks after the start of the nivolumab treatment to that before treatment between the responder and nonresponder groups (Fig. 2a, 2b). When changes in the expression of markers on PD- $1^{+} \mathrm{CD} 8^{+} \mathrm{T}$ cells before and after the nivolumab treatment were detected with the t-SNE analysis in one representative responder and one non-responder, CD103 expression on PD- $1^{+} \mathrm{CD} 8^{+} \mathrm{T}$ cells 2 weeks after the start of the nivolumab treatment was more prominent in the responder than in the non-responder, and this cell population highly co-expressed ICOS, Ki-67, and CD27 with the lower expression of Tim-3 and CD45RA (Supplementary Fig. $3)$.

\section{Analysis of functional characteristics of $\mathrm{CD} 103^{+} \mathrm{PD}-1^{+} \mathrm{CD} 8^{+} \mathrm{T}$ cells}

To characterize the phenotype and functions of the $\mathrm{CD} 103^{+} \mathrm{PD}-1^{+} \mathrm{CD} 8^{+} \mathrm{T}$ cell subset, we analyzed proliferative activity and cytotoxicity in the following subsets: CD $103^{+} \mathrm{PD}-1^{+} \mathrm{CD} 8^{+} \mathrm{T}$ cells, CD103-PD$1^{+} \mathrm{CD} 8^{+} \mathrm{T}$ cells, and PD-1 ${ }^{-} \mathrm{CD} 8^{+} \mathrm{T}$ cells. Among the three groups, the highest frequency of Ki- 67 was observed in $\mathrm{CD} 103^{+} \mathrm{PD}-1^{+} \mathrm{CD} 8^{+} \mathrm{T}$ cells before the nivolumab treatment. Moreover, the frequency of Ki-67 
increased 2 weeks and decreased 6 weeks after the start of the nivolumab treatment among all three subsets, with the largest increase in the frequency of Ki- 67 occurring among CD $103^{+} \mathrm{PD}-1^{+} \mathrm{CD} 8^{+} \mathrm{T}$ cells. (Fig. 3a). The majority of $\mathrm{CD} 103^{+} \mathrm{PD}-1^{+} \mathrm{CD} 8^{+} \mathrm{T}$ cells expressed $\mathrm{Ki}-67$ in the tSNE-analysis and a strong correlation was observed between the expression of $\mathrm{CD} 103$ and $\mathrm{Ki}-67$ on $\mathrm{PD}-1^{+} \mathrm{CD} 8^{+} \mathrm{T}$ cells

(Supplementary Fig. $3,4 a, 4 b$ ). Regarding cytotoxicity and the activation status, $C D 103^{+} \mathrm{PD}-1^{+} \mathrm{CD} 8^{+} \mathrm{T}$ cells had lower frequencies of perforin and granzyme than the other subsets at all time points, but higher frequencies of INF- $y$, TNF-a, and IL-2 2 weeks after the start of the nivolumab treatment (Fig. 3b, 3c). These results suggest that $\mathrm{CD} 103^{+} \mathrm{PD}-1^{+} \mathrm{CD} 8^{+} \mathrm{T}$ cell subsets are highly proliferative and less cytotoxic, but strongly activated.

We examined the differentiation status of T cells characterized by the naïve T cell marker, CD45RA, and the differentiation T cell marker, $C D 27$ among the naive $\left(C D 45 R A^{+} C D 27^{+}\right)$, central memory $\left(C D 45 R^{-}\right.$ $\mathrm{CD}^{2} 7^{+}$), effector memory (CD45RA-CD27), and terminally differentiated (CD45RA ${ }^{+}$CD27') subsets (Supplementary Fig. 5a) $(8,11-16)$. In this classification, the central memory subset was dominant in PD$1^{+} \mathrm{CD} 8^{+} \mathrm{T}$ cells, particularly in $\mathrm{CD} 103^{+} \mathrm{PD}-1^{+} \mathrm{CD} 8^{+} \mathrm{T}$ cells, and the percentage of this subset significantly increased after the nivolumab treatment (Fig. 3d, Supplementary Fig. 5b).

\section{The relationship between an increase in the subset of $\mathrm{CD} 103^{+} \mathrm{PD}-1^{+} \mathrm{CD} 8^{+} \mathrm{T}$ cells and patient prognosis}

When patients were divided into the high and low groups based on the median value of the frequency of CD103 among PD $-1^{+} C D 8^{+} T$ cells 2 weeks after treatment, the high group had significantly better PFS than the low group ( $P=0.032$, Fig. $4 \mathrm{a})$. In the analysis for the ratio of the frequency of CD103 among PD$1^{+} \mathrm{CD} 8^{+} \mathrm{T}$ cells in peripheral blood 2 weeks after the start of the nivolumab treatment to that before treatment (\%CD103 $2 \mathrm{w} / \mathrm{pre})$, the high group also had significantly better PFS than the low group $(P=0.007$; Fig. 4b). Similar results were observed in the analysis of the actual cell number of $C D 103^{+} P D-1^{+} C D 8^{+} T$ cells/ $\mu \mathrm{l} 2$ weeks after the start of treatment (Supplementary Fig. 6a, 6b). Furthermore, a multivariate analysis of clinicopathologic variables revealed that the ratio of the frequency of CD103 among PD$1^{+} \mathrm{CD} 8^{+} \mathrm{T}$ cells in peripheral blood 2 weeks after treatment to that before treatment (\%CD103 $\left.2 \mathrm{w} / \mathrm{pre}\right)$ was an independent prognostic factor for PFS (HR: 3.09, 95\% Cl: 1.19-8.79; $P=0.020$, Supplementary Table S1).

\section{Evaluation of nivolumab-binding T cells in tumors and lymph nodes resected after the nivolumab treatment}

Tumors, lymph nodes, and peripheral blood were collected from two individual patients (cases 1 and 2) who were treated with nivolumab, showed a durable response, and subsequently underwent gastrectomy. We detected the presence of nivolumab-binding $C D 8^{+} \mathrm{T}$ cells in tumors, lymph nodes, and peripheral blood (Fig. 5a). The majority of nivolumab-binding $\mathrm{CD} 8^{+}$tumor-infiltrating lymphocytes (TILs) expressed CD103, while a relatively high percentage of nivolumab-binding T cells from lymph nodes expressed CD103 in contrast to a lower percentage in peripheral blood (Fig. 5b). Regarding the 
differentiation status, $\mathrm{CD} 103^{+} \mathrm{PD}-1^{+} \mathrm{CD} 8^{+} \mathrm{T}$ cells in lymph nodes consisted of the highest percentage of central memory $T$ cells, whereas effector memory $T$ cells were more frequently observed among the CD $103^{+} \mathrm{PD}-1^{+} \mathrm{CD} 8^{+} \mathrm{T}$ cells of TILs (Fig. $5 \mathrm{c}$ ). The differentiation status of CD $103^{+} \mathrm{PD}-1^{+} \mathrm{CD} 8^{+} \mathrm{T}$ cells in peripheral blood was between that of the lymph nodes and tumors. The frequency of Ki-67 among $\mathrm{CD} 103^{+} \mathrm{PD}-1^{+} \mathrm{CD} 8^{+} \mathrm{T}$ cells was similar between the three samples (Fig. $5 \mathrm{~d}$ ).

\section{Discussion}

Although immunotherapy has evolved as a cancer treatment with the development of ICls, therapeutic efficacy is limited to a few patients. Therefore, there is an urgent need to identify biomarkers that predict the therapeutic efficacy of ICls. In the present study, we identified a peripheral blood-based biomarker that predicts responses to anti-PD- 1 therapy in gastric cancer. The ratio of the frequency of CD103 among PD$1^{+} \mathrm{CD} 8^{+} \mathrm{T}$ cells in peripheral blood 2 weeks after the start of treatment with nivolumab to that before treatment predicted responses to and survival after anti-PD-1 therapy. To the best of our knowledge, this is the first study to describe the importance of CD103 expression on PD- $1^{+} \mathrm{CD} 8^{+} \mathrm{T}$ cells after anti-PD-1 therapy in peripheral blood.

CD103, also known as integrin aE 37 , is a well-known marker for tissue-resident memory T cells, which are poised to rapidly respond to local pathogen re-encounters in peripheral tissues (17). This molecule is a transmembrane heterodimer complex that mediates the cell adhesion, migration, and homing of lymphocytes through their binding to E-cadherin on the surface of epithelial cells $(18,19)$. Therefore, CD103 favors the location and retention of resident memory T cells close to malignant cells in tumors by binding to E-cadherin on malignant cells, and the CD103-E-cadherin interaction is required for the polarized exocytosis of lytic granules causing target cell death (20). Since tissue-resident memory T cells are considered to enhance tumor immunity, the abundance of $\mathrm{CD} 103^{+} \mathrm{CD} 8^{+}$TILs had been identified as a superior prognostic factor in several cancers $(19,21,22)$. Moreover, anti-PD-1 therapy significantly increased the production of IFN- $\gamma$ in $\mathrm{CD} 103^{+} \mathrm{CD} 8^{+} \mathrm{TILs}$, and the elevated number of $\mathrm{CD} 103^{+} \mathrm{CD} 8^{+} \mathrm{TILS}$ after anti-PD-1 therapy correlated with a good response by patients with malignant melanoma $(23,24)$, suggesting the importance of $\mathrm{CD} 103^{+} \mathrm{CD} 8^{+} \mathrm{T}$ cell infiltration into tumors treated with ICls. However, the function of $\mathrm{CD} 103^{+} \mathrm{CD} 8^{+} \mathrm{T}$ cells in peripheral blood related to ICls remains unclear. In the present study, CD103-expressing $\mathrm{CD}^{+} \mathrm{T}$ cells were rarely detected in peripheral blood before nivolumab treatment, whereas CD 103-expressing CD $8^{+} \mathrm{T}$ cells increased after nivolumab treatment, particularly in $\mathrm{PD}-1^{+} \mathrm{CD} 8^{+} \mathrm{T}$ cells. The increased frequency of CD103 in PD- $1^{+} \mathrm{CD} 8^{+} \mathrm{T}$ cells in peripheral blood after nivolumab treatment correlated with a good response and better prognosis after anti-PD-1 therapy. Therefore, the increases of $\mathrm{CD} 103^{+} \mathrm{PD}-1^{+} \mathrm{CD} 8^{+} \mathrm{T}$ cells in peripheral blood may be used as a marker to predict good treatment efficacy.

The efficacy of ICls depends on the existence of tumor antigen-specific T cells (25). Two major studies proved the activation of tumor antigen-specific T cells in peripheral blood after treatment with ICls (26, 27). Although some markers were used to capture tumor antigen-specific T cells, including CD107a, 
CD39, CD103, CD154, and CD137, there has been no definite marker for tumor antigen-specific T cells (28-31). Nevertheless, some studies showed that $\mathrm{CD} 103^{+} \mathrm{CD} 8^{+} \mathrm{T}$ cells in tumors contained tumorreactive $C D 8^{+} T$ cells in several cancers $(22,32,33)$. Consistent with previous findings, the present results suggest that $\mathrm{CD} 103^{+} \mathrm{PD}-1^{+} \mathrm{CD} 8^{+} \mathrm{T}$ cells in peripheral blood contained tumor-reactive $\mathrm{CD} 8^{+} \mathrm{T}$ cells because this cell population correlated with a good clinical response to and better survival after treatment with ICls. Actually, tumor antigen-specific $\mathrm{CD} 8^{+} \mathrm{T}$ cells were identified from $\mathrm{PD}-1^{+} \mathrm{CD} 8^{+} \mathrm{T}$ cells in the peripheral blood of melanoma patients, and this is consistent with our hypothesis that PD-1 ${ }^{+} \mathrm{T}$ cells contain tumor antigen-specific CD8 ${ }^{+} \mathrm{T}$ cells (34). Although experiments were not performed to assess the tumor cell-killing activity of $\mathrm{CD} 103^{+} \mathrm{PD}-1^{+} \mathrm{CD} 8^{+} \mathrm{T}$ cells, the present results support the hypothesis that tumor antigen-specific $\mathrm{T}$ cells are present in $\mathrm{CD} 103^{+} \mathrm{PD}-1^{+} \mathrm{CD} 8^{+} \mathrm{T}$ cells in peripheral blood after nivolumab treatment and activate anti-tumor immunity.

Memory $T$ cells facilitate immunosurveillance and recall responses to reinvading pathogens. Two types of memory $T$ cells have been defined from peripheral blood: central memory $T$ cells residing in secondary lymphoid tissues with a high potential for self-renewal and effector memory $T$ cells abundant in nonlymphoid tissues with cytotoxic properties. Central memory $T$ cells become effector memory $T$ cells by a re-stimulation with various antigens and ultimately become effector $\mathrm{T}$ cells that exhibit killing activity (35). As for a relationship between memory T cells and the anti-tumor effects of ICls, an increased subset of central memory $T$ cells in peripheral blood predicted a good clinical response to ICls, while the effector memory $T$ cell subset in tumors was the major phenotype that expanded in patients who responded to ICls (36),(37). The present results demonstrated that the population of central memory T cells in $\mathrm{CD} 103^{+} \mathrm{PD}-1^{+} \mathrm{CD} 8^{+} \mathrm{T}$ cells after the nivolumab treatment was higher in lymph nodes than in peripheral blood or tumors, whereas effector memory $T$ cells increased in the $C D 103^{+} \mathrm{PD}-1^{+} \mathrm{CD} 8^{+} \mathrm{T}$ cells of tumors. Therefore, central memory $\mathrm{T}$ cells among $\mathrm{CD} 103^{+} \mathrm{PD}-1^{+} \mathrm{CD} 8^{+} \mathrm{T}$ cells in lymph nodes may be reactivated by tumor antigens after treatment with ICls, differentiate to effector memory $\mathrm{T}$ cells, migrate through peripheral blood to tumors, and then target tumor cells with cytotoxic functions. A recent study on tumor antigen-specific $T$ cells after treatment with ICls showed that the dominant population in peripheral blood changed from central memory to effector memory $T$ cells over time after the initiation of treatment with a serial sample analysis (38). Therefore, the abundance of the central memory subtype in CD $103^{+} P D-$ $1^{+} \mathrm{CD} 8^{+} \mathrm{T}$ cells in peripheral blood may be a marker that predicts the efficacy of ICls. Further studies are needed to investigate the fate of $\mathrm{CD} 103^{+} \mathrm{PD}-1^{+} \mathrm{CD} 8^{+} \mathrm{T}$ cells during treatment with ICls.

Since the anti-PD-1 antibody binds to PD-1-expressing cells, we focused on nivolumab-binding T cells, which have been suggested to play a major role in responses to ICls, and these cells may be detected by a method using the anti-lgG4 antibody. Two previous studies using this method indicated that the early proliferative $\left(\mathrm{Ki}-67^{+}\right)$response of peripheral blood PD- $1^{+} \mathrm{CD} 8^{+} \mathrm{T}$ cells after anti-PD- 1 therapy was associated with clinical outcomes in patients with non-small cell lung cancer and thymic epithelial tumors $(6,7)$. In the present study, $\mathrm{Ki}-67^{+}$-proliferating $\mathrm{CD} 8^{+} \mathrm{T}$ cells were more frequently observed in CD $103^{+} \mathrm{PD}-1^{+} \mathrm{CD} 8^{+} \mathrm{T}$ cells than in $\mathrm{CD} 103^{-} \mathrm{PD}-1^{+} \mathrm{CD} 8^{+} \mathrm{T}$ cells or PD- $1^{-} \mathrm{CD} 8^{+} \mathrm{T}$ cells and 2 weeks after 
treatment initiation than before or 6 weeks after treatment initiation. Therefore, $C D 103^{+} P D-1^{+} C D 8^{+} T$ cells were the most proliferative and observed at an early time point after the initial treatment. These results support the use of peripheral blood monitoring for $C D 103^{+} \mathrm{PD}-1^{+} \mathrm{CD} 8^{+} \mathrm{T}$ cells at early time points after treatment initiation. Considering the mode of action of PD-1-blocking antibodies, measurements of CD103-expressing PD $-1^{+} \mathrm{CD} 8^{+} \mathrm{T}$ cells may be applicable to several cancer types. An approach to expand CD103-expressing PD- $1^{+} \mathrm{CD} 8^{+} \mathrm{T}$ cells may be important for overcoming unresponsiveness to anti-PD-1 therapy.

The present study had a number of limitations. It was performed at a single institution with a relatively small sample size and only one type of cancer was examined. Therefore, the present results need to be validated in a larger cohort and in another type of cancer. Furthermore, different antibodies were used to detect PD- $1^{+} T$ cells before and after the nivolumab treatment, namely, anti-PD-1 antibodies before treatment and anti-IgG4 antibodies after treatment. Therefore, pre- and post-treatment comparisons may not be consistent. However, since no significant differences were observed in the frequency of PD-1 among $\mathrm{CD}^{+} \mathrm{T}$ cells in in vitro experiments with anti-PD-1 and anti-IgG4 antibodies, the majority of PD$1^{+} \mathrm{CD} 8^{+} \mathrm{T}$ cells were considered to be precisely detected (Supplementary Fig. 1a, 1b).

In conclusion, the present results suggest that the ratio of the frequency of $\mathrm{CD} 103$ among $\mathrm{PD}-1^{+} \mathrm{CD} 8^{+} \mathrm{T}$ cells in peripheral blood 2 weeks after the start of the nivolumab treatment to that before treatment reflects responses to and survival by patients receiving anti-PD-1 therapy. Further studies with a larger number of patients and various cancer types are needed to validate this parameter as a useful biomarker for anti-PD-1 therapy.

\section{Declarations}

\section{Acknowledgments}

We thank all the patients who contributed to this study. We thank M. Matsumoto and K. Goto for their help.

\section{Funding}

The authors declare that no funds, grants, or other support were received during the preparation of this manuscript.

\section{Competing interests}

The authors have no relevant financial or non-financial interests to disclose.

\section{Author Contributions}

Yohei Nose, Takuro Saito, and Hisashi Wada contributed to the conception or design of the work. Yohei Nose, Takuro Saito, and Kei Yamamoto performed the experiments. Miya Haruna, and Azumi Ueyama 
helped performing the experiments. Yohei Nose, Takuro Saito, Yuichiro Doki, and Hisashi Wada collected data and all authors analyzed data. Yohei Nose drafted the article. Takuro Saito, Yuichiro Doki, and Hisashi Wada helped finalize the article. All authors have read and approved the final article. All authors agreed to be accountable for all aspects of the work in ensuring that questions related to the accuracy or integrity of any part of the work are appropriately investigated and resolved.

\section{Ethics approval}

All procedures were in accordance with the Helsinki Declaration. The Human Ethics Review Committee of Osaka University Graduate School of Medicine approved the protocol for this study.

\section{Consent to participate}

Informed consent was obtained from all individual participants included in the study.

\section{References}

1. Callahan MK, Postow MA, Wolchok JD (2016) Targeting T Cell Co-receptors for Cancer Therapy. Immunity. 44: 1069-78. doi: 10.1016/j.immuni.2016.04.023

2. Topalian SL, Taube JM, Anders RA, Pardoll DM (2016) Mechanism-driven biomarkers to guide immune checkpoint blockade in cancer therapy. Nat Rev Cancer. 16: 275 - 87. doi: $10.1038 /$ nrc. 2016.36

3. Taube JM, Klein A, Brahmer JR et al. (2014) Association of PD-1, PD-1 ligands, and other features of the tumor immune microenvironment with response to anti-PD-1 therapy. Clin Cancer Res. 20: 506474. doi: 10.1158/1078-0432.Ccr-13-3271

4. Topalian SL, Hodi FS, Brahmer JR et al. (2012) Safety, activity, and immune correlates of anti-PD-1 antibody in cancer. N Engl J Med. 366: 2443-54. doi: 10.1056/NEJMoa1200690

5. Kang YK, Boku N, Satoh T et al. (2017) Nivolumab in patients with advanced gastric or gastrooesophageal junction cancer refractory to, or intolerant of, at least two previous chemotherapy regimens (ONO-4538-12, ATTRACTION-2): a randomised, double-blind, placebo-controlled, phase 3 trial. Lancet. 390: 2461-71. doi: 10.1016/s0140-6736(17)31827-5

6. Kamphorst AO, Pillai RN, Yang S et al. (2017) Proliferation of PD-1 + CD8 T cells in peripheral blood after PD-1-targeted therapy in lung cancer patients. Proc Natl Acad Sci U S A. 114: 4993-8. doi: $10.1073 /$ pnas. 1705327114

7. Kim KH, Cho J, Ku BM et al. (2019) The First-week Proliferative Response of Peripheral Blood PD$1(+)$ CD8(+) T Cells Predicts the Response to Anti-PD-1 Therapy in Solid Tumors. Clin Cancer Res. 25: 2144-54. doi: 10.1158/1078-0432.Ccr-18-1449

8. Kato R, Yamasaki M, Urakawa S et al. (2018) Increased Tim-3(+) T cells in PBMCs during nivolumab therapy correlate with responses and prognosis of advanced esophageal squamous cell carcinoma patients. Cancer Immunol Immunother. 67: 1673-83. doi: 10.1007/s00262-018-2225-x 
9. Durgeau A, Virk Y, Corgnac S, Mami-Chouaib F (2018) Recent Advances in Targeting CD8 T-Cell Immunity for More Effective Cancer Immunotherapy. Front Immunol. 9: 14. doi:

10.3389/fimmu.2018.00014

10. Osa A, Uenami T, Koyama S et al. (2018) Clinical implications of monitoring nivolumab immunokinetics in non-small cell lung cancer patients. JCI Insight. 3. doi: 10.1172/jci.insight.59125

11. Romero P, Zippelius A, Kurth I et al. (2007) Four functionally distinct populations of human effectormemory CD8 + T lymphocytes. J Immunol. 178: 4112-9. doi: 10.4049/jimmunol.178.7.4112

12. Hamann D, Baars PA, Rep MH, Hooibrink B, Kerkhof-Garde SR, Klein MR, van Lier RA (1997) Phenotypic and functional separation of memory and effector human CD8 + T cells. J Exp Med. 186: 1407-18. doi: 10.1084/jem.186.9.1407

13. Dieli F, Poccia F, Lipp M, Sireci G, Caccamo N, Di Sano C, Salerno A (2003) Differentiation of effector/memory Vdelta2 T cells and migratory routes in lymph nodes or inflammatory sites. J Exp Med. 198: 391-7. doi: 10.1084/jem.20030235

14. Caccamo N, Meraviglia S, Ferlazzo V, Angelini D, Borsellino G, Poccia F, Battistini L, Dieli F, Salerno A (2005) Differential requirements for antigen or homeostatic cytokines for proliferation and differentiation of human Vgamma9Vdelta2 naive, memory and effector $\mathrm{T}$ cell subsets. Eur $\mathrm{J}$ Immunol. 35: 1764-72. doi: 10.1002/eji.200525983

15. Appay V, van Lier RA, Sallusto F, Roederer M (2008) Phenotype and function of human T lymphocyte subsets: consensus and issues. Cytometry A. 73: 975 - 83. doi: 10.1002/cyto.a.20643

16. Odaira K, Kimura SN, Fujieda N, Kobayashi Y, Kambara K, Takahashi T, Izumi T, Matsushita H, Kakimi

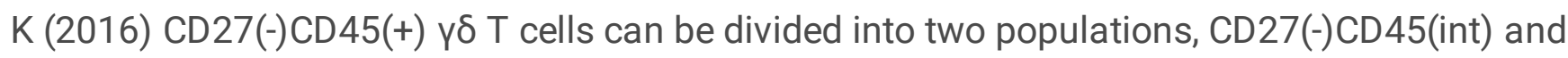
CD27(-)CD45(hi) with little proliferation potential. Biochem Biophys Res Commun. 478: 1298 - 303. doi: 10.1016/j.bbrc.2016.08.115

17. Mueller SN, Mackay LK (2016) Tissue-resident memory T cells: local specialists in immune defence. Nat Rev Immunol. 16: 79-89. doi: 10.1038/nri.2015.3

18. Boutet M, Gauthier L, Leclerc M, Gros G, de Montpreville V, Théret N, Donnadieu E, Mami-Chouaib F (2016) TGF $\beta$ Signaling Intersects with CD103 Integrin Signaling to Promote T-Lymphocyte Accumulation and Antitumor Activity in the Lung Tumor Microenvironment. Cancer Res. 76: 1757-69. doi: 10.1158/0008-5472.Can-15-1545

19. Li R, Liu H, Cao Y et al. (2020) Identification and validation of an immunogenic subtype of gastric cancer with abundant intratumoural CD103(+)CD8(+) T cells conferring favourable prognosis. Br J Cancer. 122: 1525-34. doi: 10.1038/s41416-020-0813-y

20. Mami-Chouaib F, Blanc C, Corgnac S, Hans S, Malenica I, Granier C, Tihy I, Tartour E (2018) Resident memory T cells, critical components in tumor immunology. J Immunother Cancer. 6: 87. doi: 10.1186/s40425-018-0399-6

21. Webb JR, Milne K, Watson P, Deleeuw RJ, Nelson BH (2014) Tumor-infiltrating lymphocytes expressing the tissue resident memory marker CD103 are associated with increased survival in highgrade serous ovarian cancer. Clin Cancer Res. 20: 434 - 44. doi: 10.1158/1078-0432.Ccr-13-1877 
22. Djenidi F, Adam J, Goubar A, Durgeau A, Meurice G, de Montpréville V, Validire P, Besse B, MamiChouaib F (2015) CD8 + CD103 + tumor-infiltrating lymphocytes are tumor-specific tissue-resident memory T cells and a prognostic factor for survival in lung cancer patients. J Immunol. 194: 347586. doi: 10.4049/jimmunol.1402711

23. Wang P, Huang B, Gao Y, Yang J, Liang Z, Zhang N, Fu X, Li L (2018) CD103(+)CD8(+) T lymphocytes in non-small cell lung cancer are phenotypically and functionally primed to respond to PD-1 blockade. Cell Immunol. 325: 48-55. doi: 10.1016/j.cellimm.2018.02.002

24. Edwards J, Wilmott JS, Madore J et al. (2018) CD103(+) Tumor-Resident CD8(+) T Cells Are Associated with Improved Survival in Immunotherapy-Naïve Melanoma Patients and Expand Significantly During Anti-PD-1 Treatment. Clin Cancer Res. 24: 3036-45. doi: 10.1158/1078-0432.Ccr17-2257

25. O'Donnell JS, Long GV, Scolyer RA, Teng MW, Smyth MJ (2017) Resistance to PD1/PDL1 checkpoint inhibition. Cancer Treat Rev. 52: 71-81. doi: 10.1016/j.ctrv.2016.11.007

26. Rizvi NA, Hellmann MD, Snyder A et al. (2015) Cancer immunology. Mutational landscape determines sensitivity to PD-1 blockade in non-small cell lung cancer. Science. 348: 124-8. doi:

10.1126/science.aaa1348

27. Snyder A, Makarov V, Merghoub T et al. (2014) Genetic basis for clinical response to CTLA-4 blockade in melanoma. N Engl J Med. 371: 2189-99. doi: 10.1056/NEJMoa1406498

28. Duhen T, Duhen R, Montler R et al. (2018) Co-expression of CD39 and CD103 identifies tumor-reactive CD8 T cells in human solid tumors. Nat Commun. 9: 2724. doi: 10.1038/s41467-018-05072-0

29. Balança CC, Salvioni A, Scarlata CM et al. (2021) PD-1 blockade restores helper activity of tumorinfiltrating, exhausted PD-1hiCD39 + CD4 T cells. JCl Insight. 6. doi: 10.1172/jci.insight.142513

30. Ye Q, Song DG, Poussin M, Yamamoto T, Best A, Li C, Coukos G, Powell DJ, Jr. (2014) CD137 accurately identifies and enriches for naturally occurring tumor-reactive T cells in tumor. Clin Cancer Res. 20: 44-55. doi: 10.1158/1078-0432.Ccr-13-0945

31. Baumgaertner $P$, Jandus $C$, Rivals JP et al. (2012) Vaccination-induced functional competence of circulating human tumor-specific CD8 T-cells. Int J Cancer. 130: 2607-17. doi: 10.1002/ijc.26297

32. Webb JR, Milne K, Nelson BH (2015) PD-1 and CD103 Are Widely Coexpressed on Prognostically Favorable Intraepithelial CD8 T Cells in Human Ovarian Cancer. Cancer Immunol Res. 3: 926 - 35. doi: 10.1158/2326-6066.Cir-14-0239

33. Yang R, Cheng S, Luo $\mathrm{N}$ et al. (2019) Distinct epigenetic features of tumor-reactive CD8 + T cells in colorectal cancer patients revealed by genome-wide DNA methylation analysis. Genome Biol. 21: 2 . doi: 10.1186/s13059-019-1921-y

34. Gros A, Parkhurst MR, Tran E et al. (2016) Prospective identification of neoantigen-specific lymphocytes in the peripheral blood of melanoma patients. Nat Med. 22: 433-8. doi: 10.1038/nm.4051

35. Ando $M$, Ito $M$, Srirat $T$, Kondo $T$, Yoshimura A (2020) Memory $T$ cell, exhaustion, and tumor immunity. Immunol Med. 43: 1-9. doi: 10.1080/25785826.2019.1698261 
36. Takeuchi Y, Tanemura A, Tada Y, Katayama I, Kumanogoh A, Nishikawa H (2018) Clinical response to PD-1 blockade correlates with a sub-fraction of peripheral central memory CD4 + T cells in patients with malignant melanoma. Int Immunol. 30: 13-22. doi: 10.1093/intimm/dxx073

37. Ribas A, Shin DS, Zaretsky J et al. (2016) PD-1 Blockade Expands Intratumoral Memory T Cells. Cancer Immunol Res. 4: 194-203. doi: 10.1158/2326-6066.Cir-15-0210

38. Caushi JX, Zhang J, Ji Z et al. (2021) Transcriptional programs of neoantigen-specific TIL in anti-PD1-treated lung cancers. Nature. 596: 126 - 32. doi: 10.1038/s41586-021-03752-4

\section{Tables}


Table 1

Patient characteristics at baseline $(n=29)$.

\begin{tabular}{|ll|}
\hline & $\mathbf{n}=\mathbf{2 9}(\%)$ \\
\hline Age, median (range) & $64(31-77)$ \\
\hline Sex & \\
\hline Male & $19(65.5 \%)$ \\
\hline Female & $10(34.5 \%)$ \\
\hline ECOG ${ }^{\dagger}$ performance status & \\
\hline 0 & $13(44.8 \%)$ \\
\hline 1 & $16(55.2 \%)$ \\
\hline Histology & \\
\hline Differentiated & $8(27.6 \%)$ \\
\hline Undifferentiated & $18(62.1 \%)$ \\
\hline Unknown & $3(10.3 \%)$ \\
\hline Site of metastasis & \\
\hline Lymph node & $13(44.8 \%)$ \\
\hline Liver & $11(37.9 \%)$ \\
\hline Peritoneum & $8(27.6 \%)$ \\
\hline Lung & $2(6.9 \%)$ \\
\hline Bone & $2(6.9 \%)$ \\
\hline Pleura & $1(3.4 \%)$ \\
\hline Adrenal & $1(3.4 \%)$ \\
\hline Other & \\
\hline Previous gastrectomy & \\
\hline Yes & \\
\hline No & \\
\hline Previous treatment regimens* & \\
\hline
\end{tabular}

$\mathrm{ECOG}^{\dagger}$ : Eastern Cooperative Oncology Group

*Includes treatments received in the adjuvant setting 


\begin{tabular}{|lc|}
\hline & $\mathbf{n}=\mathbf{2 9}(\%)$ \\
\hline Two & $12(41.4 \%)$ \\
\hline Three & $8(27.6 \%)$ \\
\hline More than four & $9(31.0 \%)$ \\
\hline Previous chemotherapy & $29(100 \%)$ \\
\hline Pyrimidine analogues & $28(96.6 \%)$ \\
\hline Platinum & $28(96.6 \%)$ \\
\hline Taxane & $12(41.4 \%)$ \\
\hline Irinotecan & $29(100 \%)$ \\
\hline Ramucirumab & \\
\hline Previous radiation & $2(6.9 \%)$ \\
\hline Yes & $27(93.1 \%)$ \\
\hline No & \\
\hline ECOG & †: Eastern Cooperative Oncology Group \\
\hline *Includes treatments received in the adjuvant setting \\
\hline
\end{tabular}

Table 2

Treatment results

$\mathrm{n}=\mathbf{2 9}$

Administration

Months

median (range)

$1.9(0.4-43.9)$

Number of nivolumab infusions

median (range)

$5(1-88)$

Best overall response

$\mathrm{CR}^{\dagger} / \mathrm{PR}^{\dagger} / \mathrm{SD}^{\dagger} / \mathrm{PD}^{\dagger} / \mathrm{NE}^{\dagger}$

0 / 3 / 2 / $21 / 3$

Progression-free survival (months)

median (range)

$1.8(0.4-45.5)$

Overall survival (months)

median (range)

$6.7(0.7-45.5)$

$\mathrm{CR}^{\dagger}$, complete response; $\mathrm{PR}^{\dagger}$, partial response; $\mathrm{SD}^{\dagger}$, stable disease; $\mathrm{PD}^{\dagger}$, progressive disease; $\mathrm{NE}^{\dagger}$, not evaluated 


\section{Figure 1}

Study design and expression frequency of each marker. a, Peripheral blood samples were collected from gastric cancer patients before treatment and 2 and 6 weeks after the start of the nivolumab treatment. $\mathbf{b}$, The frequency of each marker among PD- $1^{+} \mathrm{CD} 8^{+} \mathrm{T}$ cells or PD-1 ${ }^{-} \mathrm{CD} 8^{+} \mathrm{T}$ cells before treatment and 2 and 6 weeks after the start of treatment ( 0 week : $n=29,2$ weeks : $n=25,6$ weeks : $n=19)$. Values are indicated as medians. The significance of differences was calculated using the nonparametric Wilcoxon matchedpairs signed-rank test. $\left({ }^{\star} P<0.05,{ }^{\star} P P<0.01,{ }^{\star}{ }^{\star \star} P<0.001\right)$

\section{Figure 2}

The relationship between changes in expression frequency of each marker and therapeutic effect. The ratio of the frequency of each marker among PD- $1^{+} C D 8^{+} T$ cells 2 weeks (a. responder $n=4$, nonresponder $n=21$ ) and 6 weeks $(b$. responder $n=4$, non-responder $n=15$ ) after the start of treatment to the pre-treatment rate between the responder group and non-responder group based on the best overall response. Values are indicated as medians. The significance of differences was calculated using the nonparametric Mann-Whitney U test.

\section{Figure 3}

Analysis of functional characteristics of CD $103^{+} \mathrm{PD}-1^{+} \mathrm{CD} 8^{+} \mathrm{T}$ cells. Ki-67 (a), perforin, and granzyme (b) frequencies among CD $103^{+} \mathrm{PD}-1^{+} \mathrm{CD} 8^{+} \mathrm{T}$ cells, CD103-PD- $1^{+} \mathrm{CD} 8^{+} \mathrm{T}$ cells, and PD-1 ${ }^{-} \mathrm{CD} 8^{+} \mathrm{T}$ cells before treatment and 2 and 6 weeks after the start of the nivolumab treatment $(0$ week : $n=29,2$ weeks : $n=25,6$ weeks : $n=19$ ). c, Cytokine production in $\mathrm{CD} 103^{+} \mathrm{PD}-1^{+} \mathrm{CD} 8^{+} \mathrm{T}$ cells, CD103 PD $-1^{+} \mathrm{CD} 8^{+} \mathrm{T}$ cells, and PD- $1^{-}$ $\mathrm{CD}^{+} \mathrm{T}$ cells 2 weeks after the start of the nivolumab treatment $(n=1)$. $d$, The percentages of each differentiation subset in $\mathrm{CD} 103^{+} \mathrm{PD}-1^{+} \mathrm{CD} 8^{+} \mathrm{T}$ cells, CD $103^{-\mathrm{PD}}-1^{+} \mathrm{CD} 8^{+} \mathrm{T}$ cells, and PD- $1^{-\mathrm{CD}} 8^{+} \mathrm{T}$ cells 2 weeks after the start of the nivolumab treatment $(n=25)$. Values are indicated as medians. The significance of differences was calculated using the nonparametric Wilcoxon matched-pairs signed-rank test. $\left({ }^{\star} P<0.05,{ }^{\star} * P<0.01,{ }^{\star} * \star P<0.001\right)$

\section{Figure 4}

The relationship between an increase in the subset of $C D 103^{+} P D-1^{+} C D 8^{+} T$ cells and patient prognosis. Kaplan-Meier curves of PFS in patients with a high or low frequency of CD103 among PD $-1^{+} \mathrm{CD} 8^{+} \mathrm{T}$ cells 2 weeks after the start of the nivolumab treatment (a. $n=25)$, and those with a high or low ratio of the frequency of CD103 among PD $-1^{+} \mathrm{CD} 8^{+} \mathrm{T}$ cells in peripheral blood 2 weeks after the start of the 
nivolumab treatment to that before treatment $(\mathbf{b} . \mathrm{n}=25)$. The median of each value was used as the cutoff. The significance of differences was calculated using the Log-rank test.

\section{Figure 5}

Evaluation of nivolumab-binding T cells in tumors and lymph nodes resected after the nivolumab treatment. Marker expression frequency in samples from two patients who underwent surgical resection after the nivolumab treatment. a, PD-1 frequency among CD8 ${ }^{+} \mathrm{T}$ cells in PBMCs, lymphocytes in lymph nodes, and TILs. b, CD103 frequency among PD $-1^{+} \mathrm{CD} 8^{+} \mathrm{T}$ cells (nivolumab-binding T cells) in PBMCs, lymphocytes in lymph nodes, and TILs. Subsets of differentiation markers (c) and Ki-67 (d) on CD $103^{+}$PD $-1^{+}$CD $8^{+}$T cells in PBMCs, lymphocytes in lymph nodes, and TILs $(n=1)$.

\section{Supplementary Files}

This is a list of supplementary files associated with this preprint. Click to download.

- SupplementaryFigure1.pdf

- SupplementaryFigure2.pdf

- SupplementaryFigure3.pdf

- SupplementaryFigure4.pdf

- SupplementaryFigure5.pdf

- SupplementaryFigure6.pdf

- SupplementaryTable1.pdf 